\title{
Ischemic-Reperfusion Injury Increases Matrix Metalloproteinases and Tissue Metalloproteinase Inhibitors in Fetal Sheep Brain
}

\author{
Xiaodi Chen $^{\mathrm{a}}$ Aparna Patra ${ }^{\mathrm{a}}$ Grazyna B. Sadowska ${ }^{\mathrm{a}}$ Barbara S. Stonestreet $^{\mathrm{a}}$

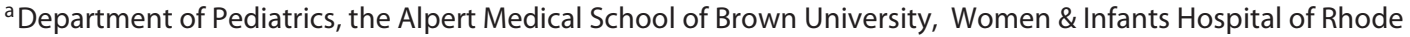 \\ Island, Providence, RI, USA
}

\section{Keywords}

Brain · Ischemia-reperfusion injury · Fetus · Matrix

metalloproteinases $\cdot$ Sheep $\cdot$ TIMPs

\begin{abstract}
Hypoxic-ischemic brain injury is a leading cause of neurodevelopmental morbidities in preterm and full-term infants. Blood-brain barrier dysfunction represents an important component of perinatal hypoxic-ischemic brain injury. The extracellular matrix (ECM) is a vital component of the bloodbrain barrier. Matrix metalloproteinases (MMPs) and tissue inhibitors of matrix metalloproteinases (TIMPs) are important ECM components. They contribute to brain development, blood-brain barrier maintenance, and to regenerative and repair processes after hypoxic-ischemic brain injury. We hypothesized that ischemia at different durations of reperfusion affects the ECM protein composition of MMPs and TIMPs in the cerebral cortex of fetal sheep. Cerebral cortical samples were snap-frozen from sham control fetuses at 127 days of gestation and from fetuses after exposure to 30-min carotid occlusion and 4-, 24-, and 48-h of reperfusion. Protein expression of MMP-2, $-8,-9$, and -13 and TIMP-1, $-2,-3$, and -4 was measured by Western immunoblotting along with the gelatinolytic activity of MMP-2 and MMP-9 by zymography. The expression of MMP- 8 was increased (Kruskal-Wallis, $p=$
\end{abstract}

(c) 2018 S. Karger AG, Basel

E-Mail karger@karger.com

www.karger.com/dne
$0.04)$ in fetuses $48 \mathrm{~h}$ after ischemia. In contrast, changes were not observed in the protein expression of MMP-2, -9 , or -13 . The gelatinolytic activity of pro-MMP-2 was increased (ANOVA, $p=0.02$, Tukey HSD, $p=0.05$ ) $24 \mathrm{~h}$ after ischemia. TIMP-1 and -3 expression levels were also higher (TIMP-1, ANOVA, $p=0.003$, Tukey HSD, $p=0.01$; TIMP-3, ANOVA, $p=0.006$, Tukey HSD, $p=0.01$ ) $24 \mathrm{~h}$ after ischemia compared with both the sham controls and with fetuses exposed to $4 \mathrm{~h}$ of reperfusion. The changes in the expression of TIMP-1, -2 , and -3 correlated with the changes in the MMP- 8 and -13 protein expression. We speculate that regulation of MMP-8, MMP13 , and TIMPs contributes to ECM remodeling after ischemic-reperfusion injury in the fetal brain.

(C) 2018 S. Karger AG, Basel

\section{Introduction}

Hypoxic-ischemic injury can impair normal brain development and is associated with disorders such as cerebral palsy, seizures, and developmental delay $[1,2]$. Major disturbances in blood-brain barrier (BBB) function are associated with hypoxic-ischemic brain injury $[3,4]$. The $\mathrm{BBB}$ consists principally of vascular endothelial cells connected by tight junctions that are surrounded by astrocytic end feet and an extracellular matrix (ECM) [3, 5-7]. 
The ECM of the basement membrane continuously undergoes controlled remodeling during development and is important in hypoxic-ischemic brain injury and pediatric stroke [8-13]. Remodeling of the ECM is facilitated primarily by matrix metalloproteinases (MMPs) and their endogenous tissue inhibitors (TIMPs) [14-16]. MMPs are a family of neutral ECM-degrading proteases including gelatinases (MMP-2 and -9) and collagenases (MMP-8 and -13) [17-20]. The expression and activity of MMPs are altered in response to hypoxic-ischemic insults and represent potential therapeutic targets in perinatal hypoxic-ischemic brain injury [11-13, 21]. TIMPs are a small family of 4 secreted protease inhibitors including TIMP-1, $-2,-3$, and -4 . They inhibit the enzymatic activity of MMPs and, consequently, regulate ECM turnover during physiological and pathological processes [22, 23].

The extent of reperfusion injury after hypoxic-ischemic insults varies considerably based upon the timing of the insult in relation to birth and the duration of time elapsed before resuscitative measures are completed. Consequently, it is important to understand the effects of different durations of reperfusion after ischemia on brain injury to determine therapeutic strategies that could attenuate the untoward effects of perinatal brain damage [24]. Accumulating evidence suggests that there is an association between BBB dysfunction and changes in MMPs and TIMPs after hypoxic-ischemic brain injury in the neonatal rodent brain $[13,25,26]$. However, the expression profiles of MMPs and TIMPs have not previously been examined after ischemia in the brain of a large mammalian fetus. We used the preclinical fetal sheep model exposed to ischemia-reperfusion-related brain injury [27] to examine the expression profiles of MMPs and TIMPs. The neurodevelopmental maturation of fetal sheep at 127 days of gestation is approximately similar to the near-term human fetal brain [28]. We have previously demonstrated increases in BBB permeability 4, 24, and $48 \mathrm{~h}$ after ischemia in the sheep fetus [4]. The objective of the present study was to examine the effects of different durations of reperfusion after ischemia on the ECM protein composition of MMPs and TIMPs in the cerebral cortex of fetal sheep.

\section{Materials and Methods}

The current study was approved by the Institutional Animal Care and Use Committees of the Warren Alpert Medical School of Brown University and of the Women \& Infants Hospital of Rhode Island, and is in accordance with the National Institutes of Health Guidelines for the use of experimental animals.

Ischemic-Reperfusion Injury and MMPs
Animal Preparation, Study Groups, and Experimental Design

We obtained cerebral cortical samples from fetal sheep at 127 days $(85 \%$ gestation; term $=147$ days $)$ after they had been exposed to in utero brain ischemia and to 1 of 3 different durations of reperfusion. We examined the cerebral cortex as it represents an important brain region, and because we had residual frozen frontal cerebral cortical samples from our previous studies [4, 29-31]. We have recently published a detailed schematic that we have used for our brain sample preparation in similar studies [32]. Briefly, onehalf of the fetal brain was dissected to measure regional BBB permeability for a previous study [4]. A coronal brain section of another half of the fetal brain was obtained at the level of the hypothalamus (mammillary bodies) for histopathological analysis [32]. The residual frozen brain from the frontal cortex was saved and used in prior publications $[4,29,31,32]$ and for the current study in order to maximize information obtained from this complex large animal resource. Unfortunately, although we have previously measured $\mathrm{BBB}$ permeability and tight junction proteins in some of the fetal sheep reported in the current study, we did not have sufficient residual tissue remaining from the sham control animals. This limits our ability to compare the MMP results in the current report to our previous measures of tight junction proteins and BBB permeability [4].

Surgical procedures were performed as described in detail elsewhere $[4,33]$. Briefly, surgery was performed on the pregnant ewes at $120-122$ days of gestation under ketamine $(10 \mathrm{mg} / \mathrm{kg})$ and $1-2 \%$ isoflurane anesthesia. Catheters were placed in a brachial vein and in the thoracic aorta via a brachial artery in the sheep fetus as described in our previous studies [4]. Fetal carotid arteries were exposed, and vertebral-occipital anastomoses and lingual arteries ligated to limit blood flow from the vertebral circulation and noncerebral sources, respectively [27]. Two inflatable vascular occluders (In Vivo Metric, Healdsburg, CA, USA) were then placed around each carotid artery [4].

The pregnant ewes were permitted to recover for 5-7 days postoperatively. The ewes were then randomly assigned to 4 groups: instrumented nonischemic treated (sham, $n=4-7$, sex not determined); 30 min of carotid occlusion, hereafter referred to as ischemia, with $4 \mathrm{~h}$ of reperfusion after ischemia (I/R-4, 1 male, $4 \mathrm{fe}$ males); ischemia and 24-h reperfusion (I/R-24, 4-5 males, 1-5 females); or ischemia and 48 -h reperfusion (I/R-48, 3 males, 2 females, the sex of 3 animals was not determined) [4]. Brain ischemia was induced by inflating the carotid artery occluders for $30 \mathrm{~min}$, and then deflating them for 4,24 , or $48 \mathrm{~h}$ of reperfusion. The occluders were not inflated in the sham fetal sheep. The ewe and fetus were then euthanized with an intravenous pentobarbital (100-200 mg/kg) infusion before the fetus was weighed, and its brain was quickly removed and weighed. One out of the 40 sheep enrolled in this study died before the onset of the study.

\section{Western Immunoblot}

We extracted a portion of the cerebral cortical samples in buffer F (10 mM Tris- $\mathrm{HCl}$ [pH 7.05], $50 \mathrm{~mm} \mathrm{NaCl,} 30 \mathrm{~mm}$ sodium pyrophosphate, $50 \mathrm{mM} \mathrm{NaF}, 5 \mu \mathrm{M} \mathrm{ZnCl}_{2}, 0.1 \mathrm{mM}$ sodium orthovanadate, $1 \%$ Triton X-100) with $1 \%$ complete protease inhibitor cocktail (Roche, Nutley, NJ, USA). The bicinchoninic acid protein assay (BCA; Thermo Fisher Scientific ${ }^{\mathrm{TM}}$, Waltham, MA, USA) was used to determine the total protein concentrations of the homogenates. We fractionated $20 \mu \mathrm{g}$ of total protein per well via sodium dodecyl sulfate-polyacrylamide gel electrophoresis (SDS-PAGE) 
and transferred the extracts onto polyvinylidene difluoride membranes ( $0.2 \mu \mathrm{m}$; Bio-Rad Laboratories, Hercules, CA, USA) using a semi-dry technique. We probed the immunoblotted membranes with primary rabbit polyclonal antibodies for MMP-8 and MMP13 (Bioss Antibodies, Woburn, MA, USA), TIMP-1 (EMD Millipore, Billerica, MA, USA), TIMP-2, and TIMP-4 (Abbiotec LLC, San Diego, CA, USA) at a dilution of 1:5,000 and used primary mouse monoclonal antibodies to probe for TIMP-3 (Lifespan Biosciences, Seattle, WA, USA) at a dilution of 1:5,000, and for MMP-2 and MMP-9 (biotin-conjugated; Lifespan Biosciences), vinculin (Thermo Fisher Scientific ${ }^{\mathrm{TM}}$ ), and $\beta$-actin (Bio-Rad Laboratories) at a dilution of 1:10,000. After an overnight incubation at $4^{\circ} \mathrm{C}$, the membranes were then incubated for $1 \mathrm{~h}$ with goat anti-rabbit (Alpha Diagnostic, San Antonio, TX, USA) for MMP-8, MMP-13, TIMP-1, TIMP-2, and TIMP-4, or with goat anti-mouse (Thermo Fisher Scientific ${ }^{\mathrm{TM}}$ ) for TIMP-3, vinculin, and $\beta$-actin, and with streptavidin-horseradish peroxidase conjugates (Thermo Fisher Scientific $^{\mathrm{TM}}$ ) for MMP-2 and MMP-9, at a dilution of 1:10,000.

We visualized the signals using enhanced chemiluminescence (ECL Prime; GE Healthcare Bio-Sciences, Pittsburgh, PA, USA) before exposure to autoradiographic film (Phenix, Candler, NC, USA). We detected pro-MMP-2, cleaved-MMP-2, MMP-8, MMP13, TIMP-1, TIMP-2, TIMP-3, TIMP-4, $\beta$-actin, and vinculin bands at $72,64,53,54,26,24,26,25,42$, and $117 \mathrm{kDa}$, respectively. Omission of the primary antibodies eliminated the chemiluminescent signals, thereby establishing the specificity of the primary antibodies to detect the specific protein bands. The expected bands for pro-MMP-9 and cleaved-MMP-9 were 92 and $83 \mathrm{kDa}$, respectively. However, we detected pro-MMP-9 and cleaved-MMP-9 bands at a range of $50-75 \mathrm{kDa}$. We speculate that these ranges are a result of factors including specificity of the primary antibodies, animal species, or posttranslational protein modifications.

All experimental samples were normalized to an internal control (IC) protein standard sample derived from the brain of a single adult sheep. Our laboratory has previously described the use of the IC sample as a reference standard for immunoblots to ensure consistent quality of loading and transferring, and to control for variability across gels [4, 34-37]. We employed this method in our laboratory because our initial studies showed that most of the traditional housekeeping protein standards are affected by development and ischemic injury in sheep, thereby necessitating an alternative normalization method. We have previously shown direct linear correlations between integrated optical density (IOD) values normalized to the IC samples and those normalized to $\beta$-actin, when one age group was studied, e.g., newborn lambs [38]. In addition, we have compared claudin-3 expression normalized as the ratio to the IC standard with values normalized as ratios to vinculin and found that the values demonstrated an excellent correlation [31]. Therefore, experimental autoradiographic values are expressed as IOD ratios to the IC samples in order to normalize comparisons between the different groups and immunoblots. Similar normalizing techniques have also been reported by others [13]. Vinculin or $\beta$-actin was further used as a loading control to verify equal loading in each lane.

\section{Gelatin Zymography}

The gelatinolytic activities of cerebral cortical MMP-2 and MMP-9 were measured by gelatin zymography. The frozen cerebral cortical tissues were homogenized (100-150 mg) on ice using a lysis buffer that contained $50 \mathrm{mM}$ Tris- $\mathrm{HCl}(\mathrm{pH} 7.4), 150 \mathrm{mM}$ $\mathrm{NaCl}, 1 \%$ nonidet $\mathrm{P}-40,0.1 \%$ SDS, $0.1 \%$ deoxycholic acid, and $1 \%$ complete protease inhibitor cocktail (Roche) for $2 \mathrm{~h}$. The homogenates were centrifuged at $16,000 \mathrm{~g}$ and $4^{\circ} \mathrm{C}$ for $10 \mathrm{~min}$ to remove any insoluble material. Total protein concentrations of the homogenates were determined with a BCA protein assay. Samples of 33.3 $\mu \mathrm{g}$ of protein along with MMP-2/MMP-9 protein standards (human recombinant MMP-2 and MMP-9 proteins; EMD Millipore) were electrophoresed on $10 \%$ Novex Zymogram gelatin gels (Thermo Fisher Scientific ${ }^{\mathrm{TM}}$ ) for $90 \mathrm{~min}$ at $120 \mathrm{~V}$ before incubation in Novex Zymogram renaturing buffer (Thermo Fisher Scienti$\mathrm{fic}^{\mathrm{TM}}$ ) for $30 \mathrm{~min}$. Thereafter, the renaturing buffer was removed, and the gels gently agitated in Novex Zymogram developing buffer (ThermoFisher Scientific ${ }^{\mathrm{TM}}$ ) at room temperature for $30 \mathrm{~min}$. The developing buffer was removed before incubating the gel overnight in fresh buffer at $37^{\circ} \mathrm{C}$. After the overnight incubation, the gel was rinsed thrice with deionized water for 5 min each and gently agitated with the staining solution (40\% methanol, $10 \%$ acetic acid, $0.5 \%$ Coomassie blue R-250) for $1.5 \mathrm{~h}$ at room temperature. The gels were then destained by gentle agitation with the destaining solution (40\% methanol, 10\% acetic acid) for 2-4 h. Areas of proteolytic activity appeared as clear bands against a blue background where gel substrate had been digested by the protease.

\section{Measurement of BBB Transfer Constant $\left(K_{i}\right)$}

The BBB transfer constant $\left(K_{i}\right)$ used in the present study was from the same cohort of animals reported in our previous studies $[4,29,31]$ and was measured with the BBB tracer $\alpha-\left[{ }^{14} \mathrm{C}\right]-$ aminoisobutyric acid (AIB; 103 Da; American Radiolabeled Chemicals, Inc., St. Louis, MO, USA), as previously described in detail $[4,39]$. Briefly, $\alpha-\left({ }^{14} \mathrm{C}\right)-\mathrm{AIB}(27.6 \pm 5.7 \mu \mathrm{Ci} / \mathrm{kg}$, mean $\pm \mathrm{SD})$ was rapidly injected intravenously, and arterial plasma $\alpha-\left({ }^{14} \mathrm{C}\right)$ AIB concentrations were obtained both before and after injection. Brain vascular volume was determined by intravenously administering ${ }^{99 \mathrm{~m}} \mathrm{Tc}$-radiolabeled red blood cells (RBCs) to the fetus $2 \mathrm{~min}$ before the end of the studies [4, 39].

Fetal plasma and cerebral cortex were prepared and radioactivity was quantified for $\alpha-\left[{ }^{14} \mathrm{C}\right]$-AIB as previously described $[4,39]$. Knowledge of the plasma concentration profile and tracer concentration in the parenchyma allows for calculation of the $K_{i}[4,39]$ :

$$
K_{i}\left(\mu \mathrm{L} \times \mathrm{g}_{\text {brain }}{ }^{-1} \times \mathrm{min}^{-1}\right) \text { given by: } K_{i}=\mathrm{A}_{\mathrm{br}} / \int_{\mathrm{o}}^{\mathrm{t}} \mathrm{c}_{\mathrm{p}}(T) \mathrm{d} T
$$

where $A_{b r}$ is the amount of tracer that crossed the BBB from blood to brain during the tracer study $\left(\mathrm{dpm} \times \mathrm{g}^{-1}\right)$, and $c_{\mathrm{p}}$ is the tracer concentration in plasma $\left(\mathrm{dpm} \times \mu \mathrm{L}^{-1}\right)$ at time $\mathrm{t}(\mathrm{min})$. $\mathrm{A}_{\mathrm{br}}$ is obtained by correcting the total amount of isotope measured in the tissue, $A_{m}\left(\mathrm{dpm} \times \mathrm{g}^{-1}\right)$, for the residual part remaining in the brain vasculature space, which is measured by ${ }^{99 \mathrm{~m}} \mathrm{Tc}$-labeled RBCs. Thus, $A_{b r}=A_{m}-V_{p} c_{p}$, where $V_{p}$ is the blood volume in brain tissue $\left(\mu \mathrm{L} \times \mathrm{g}^{-1}\right) \cdot \mathrm{V}_{\mathrm{p}}=\mathrm{A}_{\mathrm{m}}^{\dagger} / \mathrm{c}_{\mathrm{p}}^{\dagger}$, where $\mathrm{A}_{\mathrm{m}}^{\dagger}$ and $\mathrm{c}_{\mathrm{p}}^{\dagger}$ have the same definitions as $A_{m}$ and $c_{p}$, respectively, except that they apply to the ${ }^{99}$ Tc-labeled RBCs $[4,39]$. However, the samples in the current study represented residual tissue samples from our former work, and, unfortunately, we did not have sufficient tissue remaining from the sham control sheep, thereby limiting comparisons between the $K_{i}$ values and MMPs.

\section{Densitometric Analysis}

A Gel-Pro Analyzer (Media Cybernetics, Silver Spring, MD, USA) was used to measure relative band intensities. Experimental densitometry values for gelatinolytic activity in each study group were normalized to the average of 3 adult cerebral cortical samples. 
Fig. 1. Representative Western immunoblots and bar graphs of cleaved- (a, d) and pro-MMPs (b, d). MMP-2 (a, b) and MMP-9 (d, e) expression in the fetal sheep cerebral cortex obtained from the sham group $(n=5)$ and 4 - $(n=5), 24-(n=5)$, and 48 -h $(n=5)$ groups after ischemia. The expression levels of cleaved-and pro-MMP-2 and -9 were determined by calculating the ratio of integrated optical density (IOD) values of cerebral cortex from each study group to the internal control (IC) sample. Means \pm SD. c, $\mathbf{f}$ Percent IOD value of the cleaved-MMP-2 (c) and MMP-9 (f) to the total IOD value of MMP-2 and -9 expression, respectively.

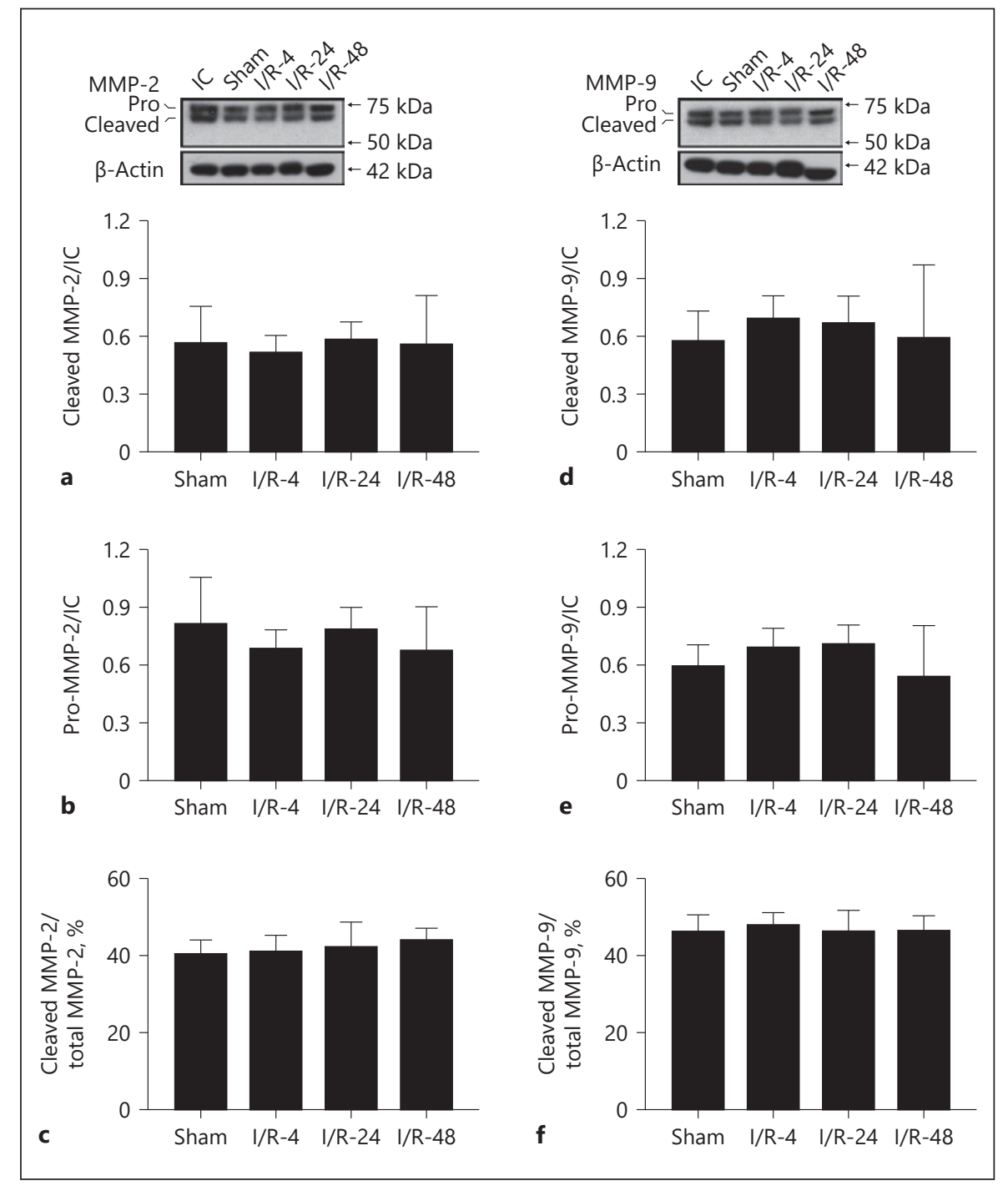

The densitometry readings of the protein expression were normalized to the average protein expression of the 3 IC values on each immunoblot, as previously described $[4,34,35,40]$. The final values represent an average of the IOD values obtained from at least 2 different immunoblots and are shown as a ratio to IC.

\section{Statistical Analysis}

The Western immunoblot and zymography results are expressed as means \pm SD. The percentages of cleaved-MMP-2/total MMP-2, pro- and cleaved-MMP-9, cleaved-MMP-9/total MMP-9, pro-MMP-2 zymography, TIMP-1, -2, and -3 were normally distributed based upon the Shapiro Wilk's W normality test. The differences in brain MMP and TIMP expressions were analyzed by 1-way analysis of variance (ANOVA). If a significant difference was detected, Tukey's honest significant difference (HSD) test for multiple comparisons was used as a post hoc method. On the other hand, pro- and cleaved-MMP-2, cleaved-MMP-2 zymography, MMP-8, MMP-13, and TIMP-4 were not normally distributed. Therefore, these results were analyzed for differences between the multiple independent groups by the Kruskal-Wallis ANOVA and median test. Specific differences between these groups were determined with mean rank multiple comparison test if a significant difference was detected. In addition, a power analysis was performed to confirm that the present study had an adequate sample size to determine a minimum detectable difference. This analysis confirmed a minimum detectable difference given with our sample size achieved a power of $80 \%$ to detect differences among the means with an $\alpha$ of $p=0.05$ (SAS Institute, Cary, NC, USA).

Correlations between MMP-8 and TIMP-1, TIMP-2, TIMP-3, and between MMP-13, and TIMP-1, TIMP-2, and TIMP-3 were compared with the Pearson product-moment correlation coefficient using the STATISTICA package (Dell Statistica, Tulsa, OK, USA). Potential associations between changes in the BBB transfer constant $K_{i}$ and MMP expression were examined in the ischemic animals that were exposed to the different durations of reperfusion using stepwise multiple regression analysis. Missing values with pairwise deletions were excluded. $p<0.05$ was considered statistically significant. 


\section{Results}

Gestational age, brain weight, and fetal body weight did not differ among sham and ischemia-reperfusion groups $(4,24$, or $48 \mathrm{~h})$, as we have previously reported (data not shown) [4]. Physiological variables such as arterial $\mathrm{pH}, \mathrm{pO}_{2}$ and $\mathrm{pCO}_{2}$, heart rate, and mean arterial blood pressure values were also within the normal physiological range for our laboratory and did not change during the study periods within or between the groups (data not shown) [4, 41]. Sex differences for the MMPs or TIMPs could not be determined because of our limited sample size.

\section{MMP-2 and MMP-9 Expression and Gelatinase}

Activities after Ischemia-Reperfusion Injury in Fetal

\section{Sheep Cerebral Cortex}

The protein expression levels of pro- and cleavedMMP-2 and -9 in the cerebral cortices of the fetal sheep obtained from the sham and (4-, 24-, and 48-h) ischemiareperfusion groups detected by Western immunoblot are summarized in Figure 1, and the gelatinolytic activities measured by zymography in Figure 2. The expression of the pro- and cleaved-MMP- 2 and -9 were determined by calculating the ratio of the IOD values of the cerebral cortices from each study group to the average IC values (Fig. 1a, b, d, e), whereas gelatinolytic activities were calculated as the ratio to the average values of 3 separate adult sheep cerebral cortices. In addition, percent IOD values of cleaved-MMP-2 and -9 to total MMP-2 and -9 expression levels are also calculated (Fig. 1c, f). The values of pro-, cleaved-, and percent of cleaved-MMP-2 and -9 expression did not differ between the sham control group and the groups exposed to 4,24 , and $48 \mathrm{~h}$ of reperfusion after ischemia. However, the gelatinase activity of proMMP-2 was increased $24 \mathrm{~h}$ after ischemia compared with the sham group (Fig. 2; ANOVA, $p=0.02, F=3.79, p=$ $0.05)$. The gelatinolytic activities of cleaved-MMP-2 and pro- and cleaved-MMP-9 could not be detected by zymography in the fetal sheep cerebral cortices (data not shown).

\section{MMP-8 and -13 Collagenase Expression after Ischemic-Reperfusion Injury in Fetal Sheep Cerebral Cortex}

MMP-8 protein expression in the cerebral cortex gradually increased with increasing duration of reperfusion after ischemia and became significantly higher $48 \mathrm{~h}$ after ischemia compared with the sham group (Fig. 3a; Kruskal-Wallis test, $p<0.05)$. However, although a similar

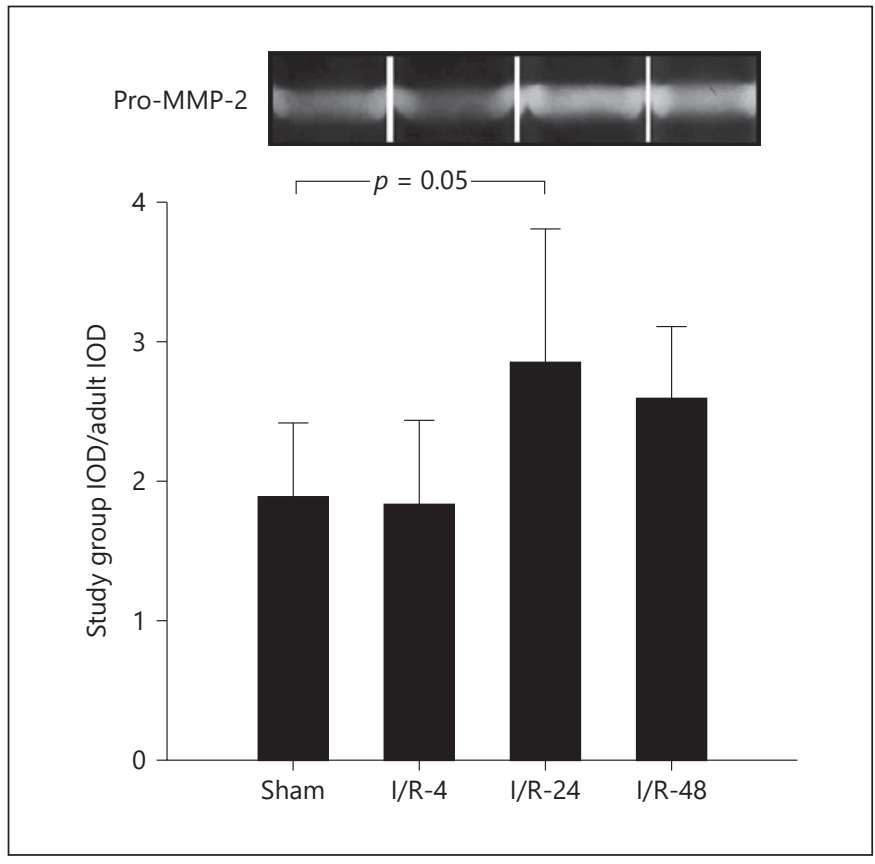

Fig. 2. Representative gelatin zymogram and bar graphs of proMMP-2 gelatinolytic activity in the fetal cerebral cortex obtained from sham $(n=7), \mathrm{I} / \mathrm{R}-4(n=5), \mathrm{I} / \mathrm{R}-24(n=9)$, and I/R-48 h $(n=$ 8 ) sheep. The activity level of pro-MMP-2 was determined by calculating the ratio of integrated optical density values of the cerebral cortex from each study group to the average of 3 adult cerebral cortical values. Means \pm SD. In the I/R-24 group, pro-MMP-2 activity was increased compared with the sham group (ANOVA, $p=$ 0.02 , Tukey HSD, $p=0.05$ ).

pattern of change was observed for MMP-13 expression, a statistically significant increase was not observed (Fig. 3 b; Kruskal-Wallis test, $p=0.06$ ).

\section{TIMP-1, -2, -3, and -4 Expression after Ischemia-}

Reperfusion Injury in Fetal Sheep Cerebral Cortex

TIMP-1, - 2, -3, and - 4 expression was determined by calculating the ratio of the IOD values of the cerebral cortices from each study group to the average IC values (Fig. 4). TIMP-1 protein expression was higher (Fig. 4a; ANOVA, $F=7.41, p<0.05) 24 \mathrm{~h}$ after ischemia compared with the values in sham-treated animals and in the group exposed to ischemia and reperfusion for $4 \mathrm{~h}$. The protein expression of TIMP-2 was higher (Fig. 4b: ANOVA, $F=$ $4.24, p<0.05) 24 \mathrm{~h}$ after ischemia compared with the group exposed to ischemia and reperfusion for $4 \mathrm{~h}$. The protein expression of TIMP-3 was higher (Fig. 4c; ANOVA, $F=6.01, p<0.05) 24 \mathrm{~h}$ after ischemia compared with the values in the sham-treated group and in the group exposed to ischemia and reperfusion for $4 \mathrm{~h}$. Although 
Fig. 3. Representative Western immunoblots and bar graphs of MMP-8 and MMP13 expression in the fetal cerebral cortex obtained from the sham $(n=5)$, ischemia/ reperfusion (I/R)-4 $(n=5),-24(n=5)$, and $-48(n=5)$ sheep. MMP-8 and MMP-13 expression gradually increased after ischemia. MMP-8 protein expression (a) was significantly higher $48 \mathrm{~h}$ after ischemia than in the sham group (Kruskal-Wallis, $p=0.04)$. However, statistical significance in MMP-13 expression (b) was not detected among the study groups (Kruskal-Wallis, $p=0.06)$. Means \pm SD. IC, internal control. ${ }^{*} p=0.05$.

Fig. 4. Representative Western immunoblots and bar graphs of TIMP-1 (a), TIMP2 (b), TIMP-3 (c), and TIMP-4 (d) expression in the fetal cerebral cortex obtained from the sham $(n=5), \mathrm{I} / \mathrm{R}-4(n=5), \mathrm{I} / \mathrm{R}-24$ $(n=5)$, and I/R-48 $(n=5)$ sheep. TIMP-1, -2 , and -3 expression levels were higher 24 than $4 \mathrm{~h}$ after ischemia. TIMP- 1 and -3 expression levels were also higher in the I/R24 group than in the sham group. TIMP-4 did not differ among groups (KruskalWallis, $p=0.15)$. Means \pm SD. IC, internal control. ${ }^{*} p<0.05$ vs. sham, ${ }^{+} p<0.05$ vs. I/R-4 (ANOVA).

Ischemic-Reperfusion Injury and MMPs
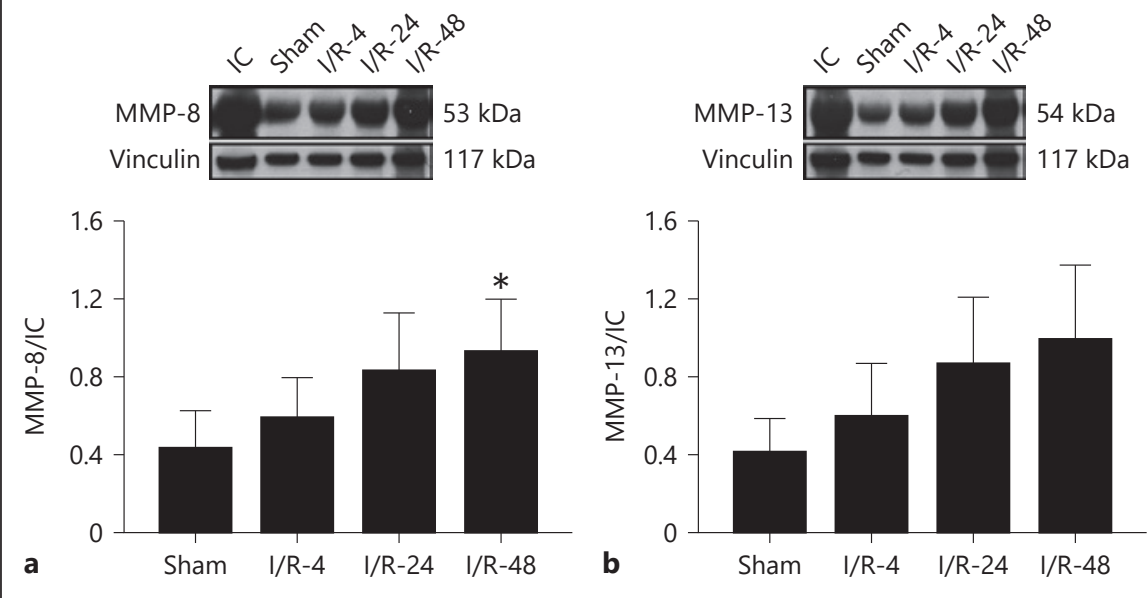

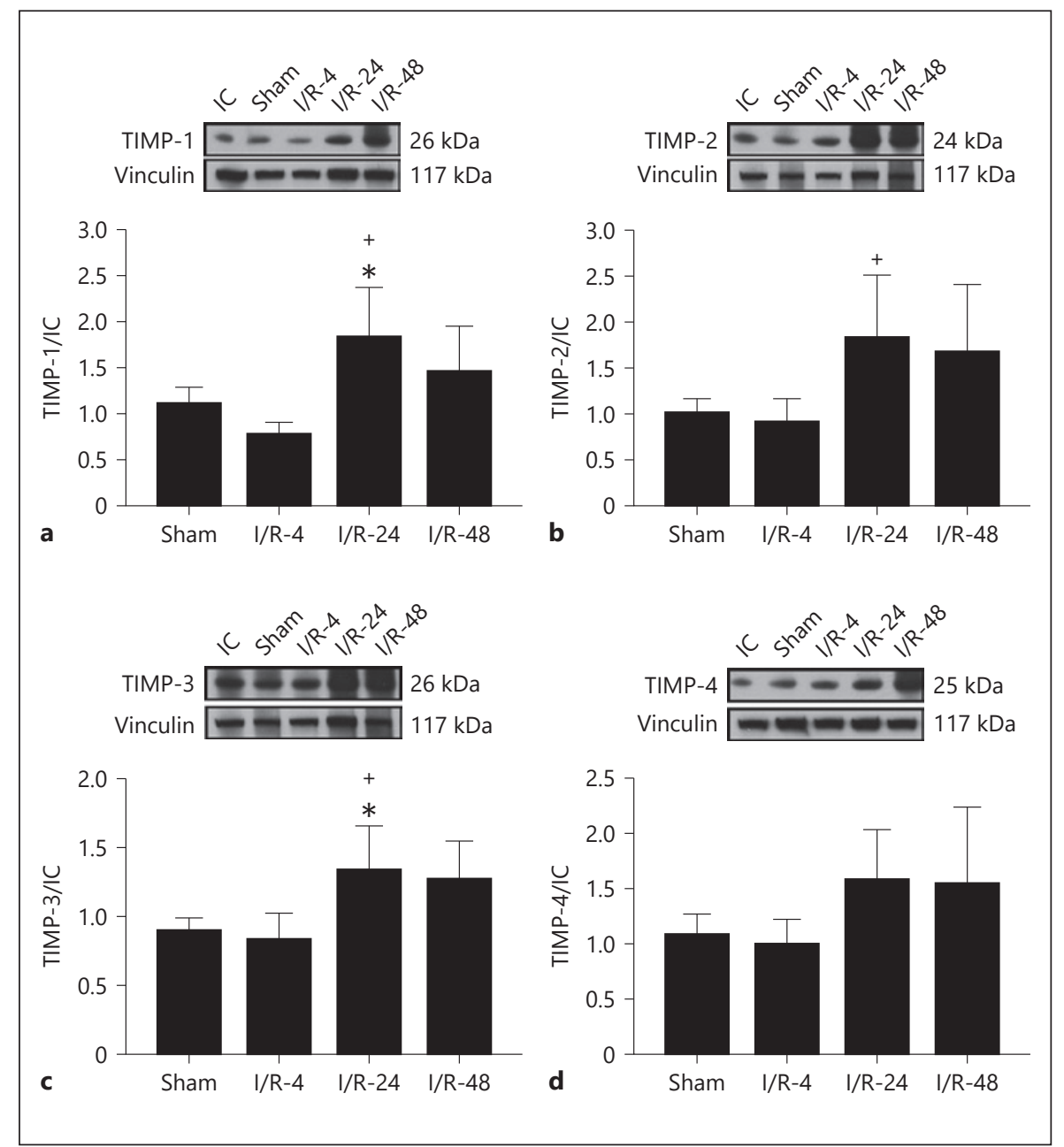


Fig. 5. TIMP-1, -2, and -3 protein expression as the ratio to the internal control (IC) standard plotted against MMP-8 and -13 values normalized as the ratio to IC. Linear regression analysis shows a positive correlation between TIMP-1 and MMP-8 $(r=$ $0.67, n=17, p<0.01)$, between TIMP-2 and MMP-8 $(r=0.71, n=20, p<0.001)$, and between TIMP-3 and MMP-8 $(r=0.77, n=$ $19, p<0.001)$, between TIMP-1 and MMP$13(r=0.66, n=17, p<0.01)$, between TIMP-2 and MMP-13 $(r=0.76, n=20, p<$ $0.001)$, and between TIMP-3 and MMP-13 $(r=0.74, n=19, p<0.001)$. Regression lines (black line) and 95\% confidence bands (dashed lines) are shown.

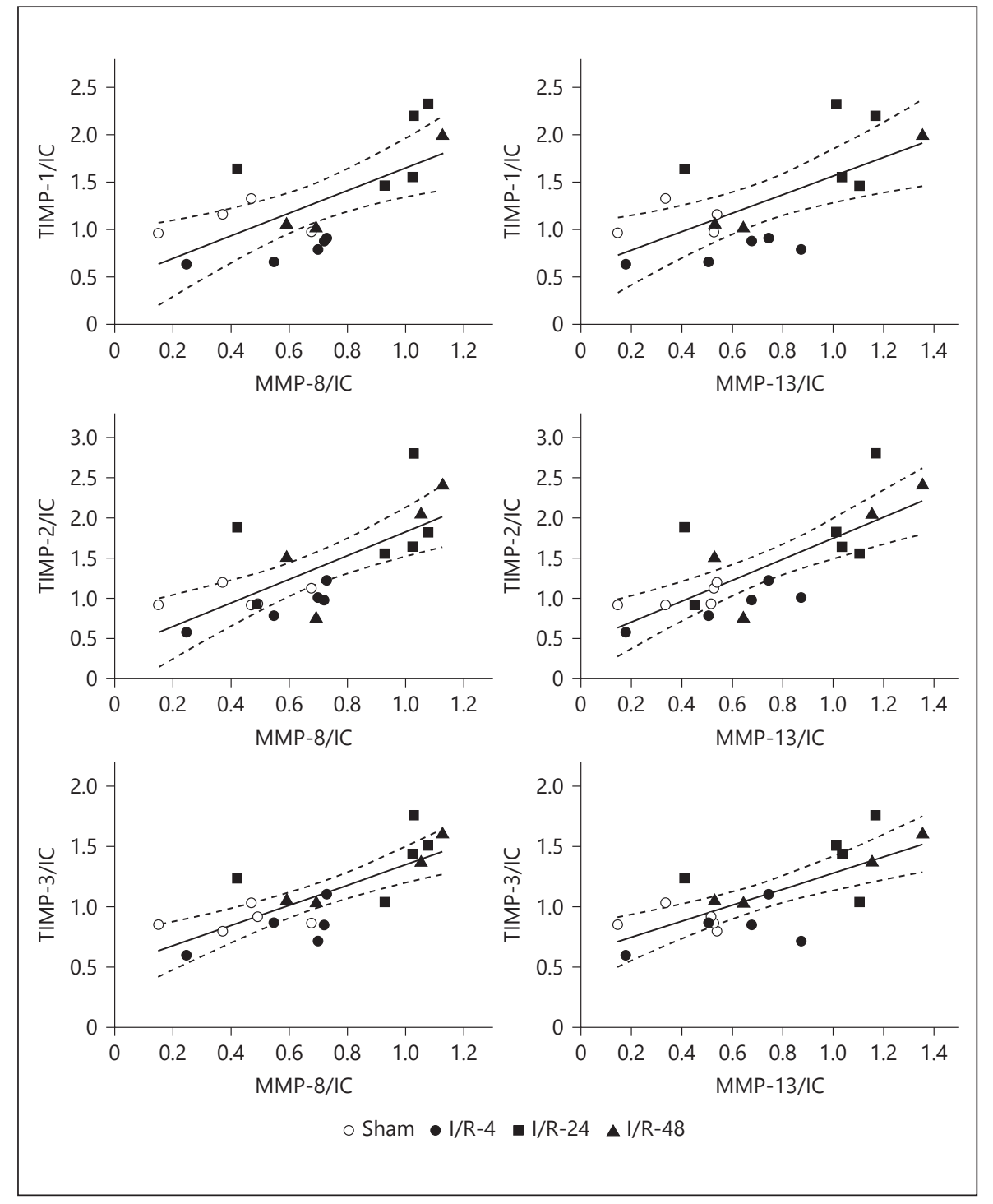

the patterns of change in TIMP-4 after ischemia were similar to those of TIMP-1, -2 , and -3 , the protein expression did not exhibit statistically significant changes after ischemia (Fig. 4d).

Correlational Analysis between MMP-8 and TIMP-1, -2 , and -3 and between MMP-13 and TIMP-1, -2, and -3 after Ischemia-Reperfusion Injury in Fetal Sheep Cerebral Cortex

We examined the correlations between MMP- 8 and TIMP- $1,-2$, and -3 because MMP- 8 and TIMP- $-1,-2$, and -3 protein expression increased after ischemia in the fetal cerebral cortex. The increases in MMP-8 values demonstrated direct linear correlations with increases in TIMP- $1(r=0.67, n=17, p=0.003)$, TIMP-2 $(r=0.71, n=20$, $p=0.0004)$, and TIMP-3 $(r=0.77, n=19, p=0.0001$; Fig. 5). We also examined the correlations between MMP13 and TIMP-1, -2 , and -3 because MMP-13 protein showed an expression pattern similar to MMP-8 $(p=$ 0.06 ) after ischemia in the fetal cerebral cortex. Similarly, MMP-13 expression values demonstrated direct linear correlations with increases in TIMP-1 $(r=0.66, n=17$, $p=0.004)$, TIMP-2 $(r=0.76, n=20, p=0.0001)$, and TIMP-3 ( $r=0.74, n=19, p=0.0003$; Fig. 5$)$. These findings suggest that increases in TIMP proteins are associated with increases in MMP- 8 and -13 protein expression after ischemia-reperfusion in fetal brain. 
Correlational Analysis between the BBB Transfer

Constant $K_{i}$ and MMP-8 and TIMP-1, -2, and -3 after

Ischemia-Reperfusion Injury in Fetal Sheep Cerebral

Cortex

We have previously identified increases in BBB permeability using the blood-to-brain transfer constant $\left(K_{i}\right)$ after brain ischemia in the same cohort of fetal sheep [4]. Hence, the changes in MMP-8 and TIMP-1, -2 , and -3 were compared to our former blood-to-brain transfer constant $\left(K_{i}\right)$ values to determine whether the changes in MMP-8 and TIMP-1, -2 , and -3 were associated with changes in the blood-to-brain transfer constant values after brain ischemia [4]. However, we did not have the blood-to-brain transfer constants from the instrumented sham control animals; therefore, the sham control animals could not be included in the analysis. The changes in the blood-to-brain transfer constant values after brain ischemia did not demonstrate correlations with the changes in MMP-8 (multiple $R=0.17, n=16, p=0.52$ ), TIMP-1 (multiple $R=0.17, n=16, p=0.53$ ), TIMP-2 (multiple $R=0.09, n=17, p=0.73$ ), or TIMP-3 (multiple $R=0.003, n=16, p=0.99$ ). These findings suggest that increases in BBB permeability may not be associated with increases in MMP-8 and TIMP-1, -2 , and -3 protein expression at these time periods after ischemia in the ovine fetus. Alternatively, the lack of values in the sham-treated subjects, long-term ischemia-reperfusion injury, and limited numbers of fetal sheep studied could have affected the results of the correlations between the BBB permeability and the MMPs and TIMPs.

\section{Discussion}

The purpose of the present study was to examine changes in the protein expression of gelatinases (MMP-2 and -9), collagenases (MMP-8 and -13), and their endogenous tissue inhibitors (TIMP-1, $-2,-3$, and -4 ) in the cerebral cortices of fetal sheep at $85 \%$ of gestation that were exposed to ischemia with reperfusion for 4,24 , or $48 \mathrm{~h}$. Although the presence of basal levels of proteolytic activity for MMP-2 and -9, and TIMP- 1 and -2 have been previously detected in primary mixed glial cultures from preterm ovine fetuses at 90 days of gestation [42], MMPs and TIMPs have not been systematically examined after brain ischemia in a large mammalian animal species. Six main findings can be derived from our study: (1) MMP-2, -9, -8 , and -13 , and TIMP- $1,-2,-3$, and -4 are expressed endogenously in the cerebral cortex in fetal life both under basal conditions and after exposure to ischemic insults;
(2) protein expression of MMP-2 and -9 does not change in the fetal cerebral cortex after ischemic injury; in contrast, the activity of pro-MMP-2 increases after ischemia; (3) MMP-8 expression gradually increases after ischemia reaching a significant difference $48 \mathrm{~h}$ after ischemia; (4) protein expression of TIMP-1, -2, and -3 increases after ischemic brain injury; (5) changes in MMP-8 and -13 protein expression show direct correlations with changes in TIMP-1, -2 , and -3 , suggesting that there is a balance between MMP-8 and -13 and some of the TIMP inhibitors of MMPs; and (6) correlations were not observed between increases in BBB permeability measured with the blood-brain transfer constant $K_{i}$ and increases in MMP-8 and TIMP-1, -2 , and -3 protein expression after ischemia in the fetal sheep brain.

Gelatinase (MMP-2 and -9) expression has been shown to vary both spatially and temporally in the CNS during development [11]. Protein expression of both MMP-2 and -9 was detected in control ovine fetal brain at $85 \%$ gestation. Consistent with our findings, mRNA expression of MMP-2 and -9 has been detected in mouse neocortex from embryonic day (E) 14 up to postnatal day (P) 0 [43]. However, only gelatinolytic activity of pro-MMP-2 could be detected in the ovine fetal brain by zymography. In contrast, we were not able to detect MMP-9 activity in the fetal brain. Our findings are consistent with previous reports showing that MMP-9 activity was not detectable in brains of mice from E18 to P120 [11], and that cleavedMMP-2 was also not detected in the nonischemic mouse brain [44].

MMP-2 and -9 play an important role in reperfusion injury after cerebral ischemia. Upregulation of MMP-2 and MMP-9 protein expression has been detected in the plasma of children and full-term neonates after arterial ischemic stroke [10]. Protein expression of cleavedMMP-2 and cleaved-MMP-9 has also been demonstrated to be increased after 24- and 48-h hypoxic-ischemic brain injury in rat pups on postnatal day 7 [13]. In the current study, we did not observe upregulation of protein expression of pro- and cleaved-MMP-2 and -9. However, the proteolytic activity of pro-MMP-2 increased after ischemia. Our findings of increased proteolytic activity of pro-MMP-2 are consistent with work showing MMP-2 activity increased in the neonatal rat brain after hypoxicischemic injury [13]. In addition, consistent with our findings, increased activity of pro-MMP-2 along with an absence of cleaved-MMP-2 was reported after focal cerebral ischemia in the adult mouse brain [44]. Increased activity of pro-MMP-2 is thought to be associated with early extravasation of plasma constituents $[45,46]$. Al- 
though reperfusion injury is thought to potentiate MMP2 and -9 proteolytic activity, it remains controversial whether MMP-2 and - 9 are activated after transient cerebral ischemia [46]. Although we did not observe increases in MMP-2 and -9 protein expression 24 and $48 \mathrm{~h}$ after ischemia in the fetal brain, activation of pro- and cleavedMMP-2 and -9 could occur at more prolonged intervals of reperfusion after ischemia.

MMP-8 and -13 expression has been observed in the developing brain [47-49]. Consistent with these reports, MMP-8 and - 13 expression was detected in the control fetal sheep brain at $85 \%$ gestation. Likewise, MMP- 8 and -13 are also important molecules implicated in ischemiareperfusion-related brain injury [50-53]. Our results illustrate a gradual increase in MMP- 8 protein expression during short-term periods of reperfusion with the highest expression exhibited $48 \mathrm{~h}$ after the ischemic insult in fetal brain. Although upregulation of MMP-8 expression has been reported after adult ischemic brain injury [54, 55], information regarding changes in MMP-8 protein expression after ischemia is sparse in the brain of subjects in the perinatal period. MMP-8 is released from activated neutrophils and modulates neuroinflammation after cerebral ischemia $[51,55,56]$. Therefore, we speculate that the delayed increase in MMP-8 after ischemia could result from delayed neutrophil infiltration after ischemia in fetal brain. Nevertheless, the role of MMP-8 in cerebral ischemia remains controversial. Some studies have suggested that MMP-8 is a critical factor for brain damage after transient focal cerebral ischemia [55], whereas other work suggests that MMP-8 could exert protective effects on ischemic brain tissue [57].

MMP-13 has also been reported to be important in ECM remodeling after cerebral ischemia, and its expression is upregulated after ischemic brain injury in rodents [53]. However, the role of MMP-13 in perinatal brain remains to be determined. Although we demonstrated a similar pattern of MMP-13 expression to that of MMP-8 after ischemic injury, the limited numbers of animals that we were able to study along with the larger standard deviation for MMP-13 could have accounted for a lack of statistical significance $(p=0.06)$.

TIMPs are naturally occurring inhibitors of MMPs expressed constitutively in brain tissue during development, injury, and tissue repair [58-60]. TIMP expression has been demonstrated in rodent brain during embryonic and early neonatal life $[43,59]$. Consistent with the findings in rodents, we detected TIMP-1, $-2,-3$, and -4 protein expression in fetal sheep brain at $85 \%$ gestation. The balance between MMPs and TIMPs is important for brain plasticity, development, and their related disorders [61]. TIMP expression can be upregulated in response to increases in MMP expression and activity in various pathologic CNS conditions $[60,62,63]$. TIMP-1, -2 , and -3 were upregulated in the fetal brain after transient ischemia, but TIMP-4 expression did not change. Previous work has suggested that TIMP-1 and -2 expression was upregulated in the plasma of children and full-term neonates after arterial ischemic stroke [10] and in the neonatal rat brain after hypoxic-ischemic injury [13]. TIMP-1, -2 , and -3 may preserve $\mathrm{BBB}$ integrity after tissue injury $[58,64]$. In this regard, we observed that TIMP- $1,-2$, and -3 upregulation showed a direct correlation with MMP-8 and -13 expression after ischemia-reperfusion injury. MMP-8 modulates neuroinflammation and is involved in $\mathrm{BBB}$ dysfunction after transient cerebral ischemia [55]. On the other hand, MMP-13 expression is increased in damaged blood vessels at the BBB and may be associated with vascular remodeling after brain ischemia [65]. Therefore, we speculate that upregulation of TIMP-1, -2 , and -3 could have limited the amount of ischemia-reperfusion-related BBB disruption via MMP-8- and/or -13-dependent mechanisms in the fetal brain [4].

Although we have previously demonstrated increases in $\mathrm{BBB}$ permeability as a function of the duration of reperfusion with maximum increases in permeability detected $4 \mathrm{~h}$ after ischemia along with persistent increases in BBB permeability 24 and $48 \mathrm{~h}$ after ischemia in the fetus [4], we were not able to detect correlations between changes in BBB permeability and increases in MMP-8 and TIMP-1, -2 , and -3 expression after ischemia. This suggests that MMP- 8 and TIMP-1, -2 , and -3 may not be primarily responsible for ischemia-reperfusion-related $\mathrm{BBB}$ damage after short-term recovery from brain ischemia in the fetus. Nevertheless, there were limitations to these analyses as we did not have BBB permeability measures from the sham control fetal sheep in this study, and the number of observations was limited. Therefore, these results need to be interpreted with caution. In addition, we did not measure MMP-8 activity. Therefore, we cannot comment upon the potential relationship between changes in MMP-8 activity and BBB and tight junction dysregulation after ischemia. Consequently, it would also be important in future studies to examine the effect of ischemia on in situ hybridization and zymography combined with the immunohistochemistry of tight junction proteins to understand the role of MMPs in BBB dysregulation after injury in the fetal brain. Moreover, MMP inhibitors have been shown to have neuroprotective effects in neonatal rodents after hypoxic-ischemic brain in- 
jury $[12,13,66]$. Inhibition of MMP- 8 activity partially restores $\mathrm{BBB}$ function in a model of human brain microvascular endothelial cells [67]. Therefore, an MMP8-specific inhibitor such as MMP-8 inhibitor I could be used in future studies to determine the effects of MMP-8 on the BBB after ischemia in the fetal sheep brain.

There is a growing body of evidence showing sexually dimorphic outcomes after hypoxic-ischemic insults in the neonatal brain [68-70]. However, we did not have sufficient numbers of fetal sheep with sex identification to detect sex-related differences in MMPs or TIMPs after brain ischemia in the fetal sheep brain. There are several other limitations to our study along with opportunities for additional studies. In the current study, we tested protein expression and enzymatic activity of MMP-2, and -9 , and protein expression of MMP-8 and -13 and TIMP-1, -2, -3, and -4 after ischemia. However, several other MMPs (e.g., MMP-1, -3, and -10) could be potentially important after ischemic brain injury, too [71]. More importantly, the proteolytic activities of MMP-8 and -13 and TIMP-1, -2 , -3 , and -4 were not determined in our study because we had limited samples available from our previous work [4, $30,31]$. In addition, it would be of interest to use quantitative methods including reverse zymography and enzyme immunoassays to measure proteolytic activities of MMPs and TIMPs. Additionally, we did not determine the levels of protein expression and proteolytic activities of MMPs and TIMPs after longer intervals of reperfusion in the fetal brain. We were not able to detect changes in MMP-2, -9, and -13 in our current study, which potentially reflects our relatively small sample size, short-term reperfusion after ischemia, and/or individual variability in the responses to ischemia. Ischemic-reperfusion injury also disrupts cerebral capillaries predisposing to cerebral edema [72]. Although the results of our current study have the limitations described above, to the best of our knowledge this is the first report of MMPs and TIMPs in the fetal sheep brain after ischemia-reperfusion-related brain injury. Our findings suggest that MMPs could be potential therapeutic targets for the ischemia-reperfusion-related brain injury in the perinatal period.

\section{Conclusions}

MMPs and TIMPs play an important role in brain development, ECM remodeling, BBB integrity, and various pathological processes $[15,19,43,60]$. In the present study, we obtained Western immunoblot data on MMP$2,-8,-9$, and -13 , and TIMP- $1,-2,-3$, and -4 expression in the cerebral cortex of fetal sheep after exposure to ischemia and reperfusion for 4,24 , and $48 \mathrm{~h}$. We conclude that MMP-2, $-8,-9$, and -13 , and TIMP-1, $-2,-3$, and -4 are present in the ovine fetal brain and that pro-MMP-2 and -8 , and TIMP- $1,-2$, and -3 are upregulated after ischemia in fetal brain. Based upon these findings, we speculate that MMPs and TIMPs play an important role in the ischemia-reperfusion-related injury in the brain during the perinatal period.

\section{Acknowledgments}

The research reported in this publication was supported by the National Institute of General Medical Sciences of the National Institutes of Health (NIH) under the following award numbers: Institutional Development Award (IDeA) from the National Institute of General Medical Sciences (NIH grant No. P30GM114750 and NIH 1R01-HD-057100). The content is solely the responsibility of the authors and does not necessarily represent the official $\mathrm{NIH}$ views.

\section{Disclosure Statement}

The authors declare no competing financial interests.

\section{References}

1 Pharoah PO: The epidemiology of chronic disability in childhood. Int Rehabil Med 1985; 7:11-17.

2 Stanley FJ: The aetiology of cerebral palsy. Early Hum Dev 1994;36:81-88.

3 Abbott NJ, Patabendige AA, Dolman DE, Yusof SR, Begley DJ: Structure and function of the blood-brain barrier. Neurobiol Dis 2010; $37: 13-25$.

Ischemic-Reperfusion Injury and MMPs
4 Chen X, Threlkeld SW, Cummings EE, Juan I, Makeyev O, Besio WG, Gaitanis J, Banks WA, Sadowska GB, Stonestreet BS: Ischemiareperfusion impairs blood-brain barrier function and alters tight junction protein expression in the ovine fetus. Neuroscience 2012; 226:89-100.

5 Baeten KM, Akassoglou K: Extracellular matrix and matrix receptors in blood-brain barrier formation and stroke. Dev Neurobiol 2011;71:1018-1039.
6 Ballabh P, Braun A, Nedergaard M: The blood-brain barrier: an overview: structure, regulation, and clinical implications. Neurobiol Dis 2004;16:1-13.

7 Banerjee S, Bhat MA: Neuron-glial interactions in blood-brain barrier formation. Annu Rev Neurosci 2007;30:235-258.

8 Fernandez-Lopez D, Natarajan N, Ashwal S, Vexler ZS: Mechanisms of perinatal arterial ischemic stroke. J Cereb Blood Flow Metab 2014;34:921-932. 
9 Kratzer I, Chip S, Vexler ZS: Barrier mechanisms in neonatal stroke. Front Neurosci 2014;8:359.

10 Buerki SE, Grandgirard D, Datta AN, Hackenberg A, Martin F, Schmitt-Mechelke T, Leib SL, Steinlin M; Swiss Neuropediatric Stroke Registry Study Group: Inflammatory markers in pediatric stroke: an attempt to better understanding the pathophysiology. Eur J Paediatr Neurol 2016;20:252-260.

11 Ranasinghe HS, Williams CE, Christophidis LJ, Mitchell MD, Fraser M, Scheepens A: Proteolytic activity during cortical development is distinct from that involved in hypoxic ischemic injury. Neuroscience 2009;158:732744 .

12 Savard A, Brochu ME, Chevin M, Guiraut C, Grbic D, Sebire G: Neuronal self-injury mediated by IL-1 $\beta$ and MMP-9 in a cerebral palsy model of severe neonatal encephalopathy induced by immune activation plus hypoxiaischemia. J Neuroinflammation 2015;12:111.

13 Chen W, Hartman R, Ayer R, Marcantonio S, Kamper J, Tang J, Zhang JH: Matrix metalloproteinases inhibition provides neuroprotection against hypoxia-ischemia in the developing brain. J Neurochem 2009;111:726-736.

$14 \mathrm{Kim} \mathrm{SH}$, Turnbull J, Guimond S: Extracellular matrix and cell signalling: the dynamic cooperation of integrin, proteoglycan and growth factor receptor. J Endocrinol 2011;209:139151.

15 Bonnans C, Chou J, Werb Z: Remodelling the extracellular matrix in development and disease. Nat Rev Mol Cell Biol 2014;15:786-801.

16 Visse R, Nagase H: Matrix metalloproteinases and tissue inhibitors of metalloproteinases: structure, function, and biochemistry. Circ Res 2003;92:827-839.

17 Candelario-Jalil E, Yang Y, Rosenberg GA: Diverse roles of matrix metalloproteinases and tissue inhibitors of metalloproteinases in neuroinflammation and cerebral ischemia. Neuroscience 2009;158:983-994.

18 Ethell IM, Ethell DW: Matrix metalloproteinases in brain development and remodeling: synaptic functions and targets. J Neurosci Res 2007;85:2813-2823.

19 Cunningham LA, Wetzel M, Rosenberg GA: Multiple roles for MMPs and TIMPs in cerebral ischemia. Glia 2005;50:329-339.

20 Rosenberg GA: Matrix metalloproteinases in neuroinflammation. Glia 2002;39:279-291.

21 Leonardo CC, Pennypacker KR: Neuroinflammation and MMPs: potential therapeutic targets in neonatal hypoxic-ischemic injury. J Neuroinflammation 2009;6:13.

22 Brew K, Nagase H: The tissue inhibitors of metalloproteinases (TIMPs): an ancient family with structural and functional diversity. Biochim Biophys Acta 2010;1803:55-71.

23 Sun J: Matrix metalloproteinases and tissue inhibitor of metalloproteinases are essential for the inflammatory response in cancer cells. J Signal Transduct 2010;2010:985132.
24 Cerio FG, Lara-Celador I, Alvarez A, Hilario E: Neuroprotective therapies after perinatal hypoxic-ischemic brain injury. Brain Sci 2013;3:191-214.

25 Bednarek N, Svedin P, Garnotel R, Favrais G, Loron G, Schwendiman L, Hagberg H, Morville $\mathrm{P}$, Mallard $\mathrm{C}$, Gressens P: Increased MMP-9 and TIMP-1 in mouse neonatal brain and plasma and in human neonatal plasma after hypoxia-ischemia: a potential marker of neonatal encephalopathy. Pediatr Res 2012; 71:63-70.

26 Moretti R, Pansiot J, Bettati D, Strazielle N, Ghersi-Egea JF, Damante G, Fleiss B, Titomanlio L, Gressens P: Blood-brain barrier dysfunction in disorders of the developing brain. Front Neurosci 2015;9:40.

27 Gunn AJ, Gunn TR, de Haan HH, Williams CE, Gluckman PD: Dramatic neuronal rescue with prolonged selective head cooling after ischemia in fetal lambs. J Clin Invest 1997;99: 248-256.

28 Back SA, Riddle A, Dean J, Hohimer AR: The instrumented fetal sheep as a model of cerebral white matter injury in the premature infant. Neurotherapeutics 2012;9:359-370.

29 Patra A, Chen X, Sadowska GB, Zhang J, Lim YP, Padbury JF, Banks WA, Stonestreet BS: Neutralizing anti-interleukin- $1 \beta$ antibodies reduce ischemia-related interleukin- $1 \beta$ transport across the blood-brain barrier in fetal sheep. Neuroscience 2017;346:113-125.

30 Petersson KH, Pinar H, Stopa EG, Faris RA, Sadowska GB, Hanumara RC, Stonestreet BS: White matter injury after cerebral ischemia in ovine fetuses. Pediatrc Res 2002;51:768-776.

31 Sadowska GB, Chen X, Zhang J, Lim YP, Cummings EE, Makeyev O, Besio WG, Gaitanis J, Padbury JF, Banks WA, Stonestreet BS: Interleukin- $1 \beta$ transfer across the bloodbrain barrier in the ovine fetus. J Cereb Blood Flow Metab 2015;35:1388-1395.

32 Chen X, Hovanesian V, Naqvi S, Lim YP, Tucker R, Donahue JE, Stopa EG, Stonestreet BS: Systemic infusions of anti-interleukin- $1 \beta$ neutralizing antibodies reduce short-term brain injury after cerebral ischemia in the ovine fetus. Brain Behav Immun 2018;67: 24-35.

33 Stonestreet BS, Sadowska GB, McKnight AJ, Patlak C, Petersson KH: Exogenous and endogenous corticosteroids modulate bloodbrain barrier development in the ovine fetus. Am J Physiol Regul Integr Comp Physiol 2000;279:R468-R477.

34 Duncan AR, Sadowska GB, Stonestreet BS: Ontogeny and the effects of exogenous and endogenous glucocorticoids on tight junction protein expression in ovine cerebral cortices. Brain Res 2009;1303:15-25.

35 Sadowska GB, Stopa EG, Stonestreet BS: Ontogeny of connexin 32 and 43 expression in the cerebral cortices of ovine fetuses, newborns, and adults. Brain Res 2009;1255:5156.
36 Malaeb SN, Hovanesian V, Sarasin MD, Hartmann SM, Sadowska GB, Stonestreet BS: Effects of maternal antenatal glucocorticoid treatment on apoptosis in the ovine fetal cerebral cortex. J Neurosci Res 2009;87:179-189.

37 Spasova MS, Sadowska GB, Threlkeld SW, Lim YP, Stonestreet BS: Ontogeny of inter- $\alpha$ inhibitor proteins in ovine brain and somatic tissues. Exp Biol Med 2014;239:724-736.

38 Kim CR, Sadowska GB, Petersson KH, Merino M, Sysyn GD, Padbury JF, Stonestreet BS: Effects of postnatal steroids on $\mathrm{Na}+\mathrm{K}+-$ ATPase activity and $\alpha_{1}$ - and $\beta_{1}$-subunit protein expression in the cerebral cortex and renal cortex of newborn lambs. Reprod Fertil Dev 2006;18:413-423.

39 Stonestreet BS, Patlak CS, Pettigrew KD, Reilly $\mathrm{CB}$, Cserr HF: Ontogeny of blood-brain barrier function in ovine fetuses, lambs, and adults. Am J Physiol 1996;271:R1594-R1601.

40 Sadowska GB, Malaeb SN, Stonestreet BS: Maternal glucocorticoid exposure alters tight junction protein expression in the brain of fetal sheep. Am J Physiol Heart Circ Physiol 2010;298:H179-H188.

41 Stonestreet BS, Le E, Berard DJ: Circulatory and metabolic effects of $\beta$-adrenergic blockade in the hyperinsulinemic ovine fetus. Am J Physiol 1993;265:H1098-H1106.

42 Weaver-Mikaere L, Gunn AJ, Bennet L, Mitchell MD, Fraser M: Inhibition of matrix metalloproteinases-2/-9 transiently reduces pre-oligodendrocyte loss during lipopolysaccharide- but not tumour necrosis factor- $\alpha$ induced inflammation in fetal ovine glial culture. Dev Neurosci 2013;35:461-473.

43 Bednarek N, Clement Y, Lelievre V, Olivier P, Loron G, Garnotel R, Gressens P: Ontogeny of MMPs and TIMPs in the murine neocortex. Pediatr Res 2009;65:296-300.

44 Fujimura M, Gasche Y, Morita-Fujimura Y, Massengale J, Kawase M, Chan PH: Early appearance of activated matrix metalloproteinase- 9 and blood-brain barrier disruption in mice after focal cerebral ischemia and reperfusion. Brain Res 1999;842:92-100.

45 Heo JH, Lucero J, Abumiya T, Koziol JA, Copeland BR, del Zoppo GJ: Matrix metalloproteinases increase very early during experimental focal cerebral ischemia. J Cereb Blood Flow Metab 1999;19:624-633.

$46 \mathrm{Lu}$ A, Clark JF, Broderick JP, Pyne-Geithman G, Wagner KR, Ran R, Khatri P, Tomsick T, Sharp FR: Reperfusion activates metalloproteinase's that contribute to neurovascular injury. Exp Neurol 2008;210:549-559.

47 Giambernardi TA, Sakaguchi AY, Gluhak J, Pavlin D, Troyer DA, Das G, Rodeck U, Klebe RJ: Neutrophil collagenase (MMP-8) is expressed during early development in neural crest cells as well as in adult melanoma cells. Matrix Biol 2001;20:577-587. 
48 Li Y, Ma Q, Halavi S, Concepcion K, Hartman RE, Obenaus A, Xiao D, Zhang L: Fetal stressmediated hypomethylation increases the brain susceptibility to hypoxic-ischemic injury in neonatal rats. Exp Neurol 2016;275: $1-10$.

49 Hillegass JM, Villano CM, Cooper KR, White LA: Matrix metalloproteinase-13 is required for zebra fish (Danio rerio) development and is a target for glucocorticoids. Toxicol Sci 2007;100:168-179.

50 Cuadrado E, Rosell A, Borrell-Pages M, Garcia-Bonilla L, Hernandez-Guillamon M, Ortega-Aznar A, Montaner J: Matrix metalloproteinase-13 is activated and is found in the nucleus of neural cells after cerebral ischemia. J Cereb Blood Flow Metab 2009;29: 398-410.

51 Owen CA, Hu Z, Lopez-Otin C, Shapiro SD: Membrane-bound matrix metalloproteinase- 8 on activated polymorphonuclear cells is a potent, tissue inhibitor of metalloproteinase-resistant collagenase and serpinase. J Immunol 2004;172:7791-7803.

52 Kimura-Ohba S, Yang Y: Oxidative DNA damage mediated by intranuclear MMP activity is associated with neuronal apoptosis in ischemic stroke. Oxid Med Cell Longev 2016; 2016:6927328.

53 Nagel S, Sandy JD, Meyding-Lamade U, Schwark C, Bartsch JW, Wagner S: Focal cerebral ischemia induces changes in both MMP-13 and aggrecan around individual neurons. Brain Res 2005;1056:43-50.

54 Cuadrado E, Rosell A, Penalba A, Slevin M, Alvarez-Sabin J, Ortega-Aznar A, Montaner J: Vascular MMP-9/TIMP-2 and neuronal MMP-10 up-regulation in human brain after stroke: a combined laser microdissection and protein array study. J Proteome Res 2009;8: 3191-3197.

55 Han JE, Lee EJ, Moon E, Ryu JH, Choi JW Kim HS: Matrix metalloproteinase- 8 is a novel pathogenetic factor in focal cerebral ischemia. Mol Neurobiol 2016;53:231-239.
56 Lee EJ, Han JE, Woo MS, Shin JA, Park EM, Kang JL, Moon PG, Baek MC, Son WS, Ko YT, Choi JW, Kim HS: Matrix metalloproteinase-8 plays a pivotal role in neuroinflammation by modulating TNF- $\alpha$ activation. J Immunol 2014;193:2384-2393.

57 Hori M, Nakamachi T, Rakwal R, Shibato J, Nakamura K, Wada Y, Tsuchikawa D, Yoshikawa A, Tamaki K, Shioda S: Unraveling the ischemic brain transcriptome in a permanent middle cerebral artery occlusion mouse model by DNA microarray analysis. Dis Model Mech 2012;5:270-283.

58 Masciantonio MG, Lee CKS, Arpino V, Mehta S, Gill SE: The balance between metalloproteinases and TIMPs. Prog Mol Biol Transl Sci 2017;147:101-131.

59 Stetler-Stevenson WG: Tissue inhibitors of metalloproteinases in cell signaling: metalloproteinase-independent biological activities. Sci Signal 2008;1:re6.

60 Fujimoto M, Takagi Y, Aoki T, Hayase M, Marumo T, Gomi M, Nishimura M, Kataoka H, Hashimoto N, Nozaki K: Tissue inhibitor of metalloproteinases protect blood-brain barrier disruption in focal cerebral ischemia. J Cereb Blood Flow Metab 2008;28:16741685.

61 Reinhard SM, Razak K, Ethell IM: A delicate balance: role of MMP-9 in brain development and pathophysiology of neurodevelopmental disorders. Front Cell Neurosci 2015;9:280.

62 Pagenstecher A, Stalder AK, Kincaid CL, Shapiro SD, Campbell IL: Differential expression of matrix metalloproteinase and tissue inhibitor of matrix metalloproteinase genes in the mouse central nervous system in normal and inflammatory states. Am J Pathol 1998;152: 729-741.

63 Aoki T, Kataoka H, Moriwaki T, Nozaki K, Hashimoto N: Role of TIMP-1 and TIMP-2 in the progression of cerebral aneurysms. Stroke 2007;38:2337-2345.

64 Menge T, Zhao Y, Zhao J, Wataha K, Gerber M, Zhang J, Letourneau P, Redell J, Shen L, Wang J, Peng Z, Xue H, Kozar R, Cox CS Jr, Khakoo AY, Holcomb JB, Dash PK, Pati S: Mesenchymal stem cells regulate blood-brain barrier integrity through TIMP3 release after traumatic brain injury. Sci Transl Med 2012; 4:161ra 150 .
65 Ueno M, Wu B, Nishiyama A, Huang CL, Hosomi N, Kusaka T, Nakagawa T, Onodera M, Kido M, Sakamoto H: The expression of matrix metalloproteinase- 13 is increased in vessels with blood-brain barrier impairment in a stroke-prone hypertensive model. Hypertens Res 2009;32:332-338.

66 Leonardo CC, Eakin AK, Ajmo JM, Collier LA, Pennypacker KR, Strongin AY, Gottschall PE: Delayed administration of a matrix metalloproteinase inhibitor limits progressive brain injury after hypoxia-ischemia in the neonatal rat. J Neuroinflammation 2008;5:34

67 Schubert-Unkmeir A, Konrad C, Slanina H, Czapek F, Hebling S, Frosch M: Neisseria meningitidis induces brain microvascular endothelial cell detachment from the matrix and cleavage of occludin: a role for MMP-8. PLoS Pathog 2010;6:e1000874.

68 Charriaut-Marlangue C, Besson VC, Baud O: Sexually dimorphic outcomes after neonatal stroke and hypoxia-ischemia. Int J Mol Sci 2017;19:E61.

69 Hill CA, Fitch RH: Sex differences in mechanisms and outcome of neonatal hypoxia-ischemia in rodent models: implications for sex-specific neuroprotection in clinical neonatal practice. Neurol Res Int 2012;2012: 867531.

70 Mirza MA, Ritzel R, Xu Y, McCullough LD, Liu F: Sexually dimorphic outcomes and inflammatory responses in hypoxic-ischemic encephalopathy. J Neuroinflammation 2015; $12: 32$.

71 Lakhan SE, Kirchgessner A, Tepper D, Leonard A: Matrix metalloproteinases and bloodbrain barrier disruption in acute ischemic stroke. Front Neurol 2013;4:32.

72 Rosenberg GA, Estrada EY, Dencoff JE: Matrix metalloproteinases and TIMPs are associated with blood-brain barrier opening after reperfusion in rat brain. Stroke 1998;29: 2189-2195 